\title{
In vitro Anti-parasitic Activity of Pelargonium X. asperum Essential Oil Against Toxoplasma gondii
}

\author{
Si-Yang Huang ${ }^{1,2 *}$, Na Yao', Jia-Kang He ${ }^{3}$, Ming Pan ${ }^{1}$, Zhao-Feng Hou', Yi-Min Fan', \\ Aifang $\mathrm{Du}^{4}$ and Jian-Ping $\mathrm{TaO}^{1}$ \\ 1 Jiangsu Key Laboratory of Zoonosis, Jiangsu Co-innovation Center for Prevention and Control of Important Animal \\ Infectious Diseases and Zoonosis, Institute of Comparative Medicine, College of Veterinary Medicine, Yangzhou University, \\ Yangzhou, China, ${ }^{2}$ Joint International Research Laboratory of Agriculture and Agri-Product Safety, The Ministry of Education \\ of China, Yangzhou University, Yangzhou, China, ${ }^{3}$ College of Animal Science and Technology, Guangxi University, Nanning, \\ China, ${ }^{4}$ Zhejiang Provincial Key Laboratory of Preventive Veterinary Medicine, College of Animal Sciences, Institute \\ of Preventive Veterinary Medicine, Zhejiang University, Hangzhou, China
}

\section{OPEN ACCESS}

Edited by:

Rebecca Ann Wingert,

University of Notre Dame,

United States

Reviewed by:

William Harold Witola,

University of Illinois

at Urbana-Champaign, United States

Fatemeh Ghaffarifar

Tarbiat Modares University, Iran

${ }^{*}$ Correspondence:

Si-Yang Huang

siyang.huang@hotmail.com

Specialty section:

This article was submitted to

Molecular Medicine,

a section of the journal

Frontiers in Cell and Developmental

Biology

Received: 12 October 2020

Accepted: 27 January 2021

Published: 18 February 2021

Citation:

Huang S-Y, Yao N, He J-K, Pan M, Hou Z-F, Fan Y-M, Du A and Tao J-P (2021) In vitro Anti-parasitic Activity of Pelargonium $X$. asperum Essential Oil Against Toxoplasma

gondii.

Front. Cell Dev. Biol. 9:616340. doi: 10.3389/fcell.2021.616340
Toxoplasmosis is a global zoonotic disease, and one-third of the human population is chronically infected by Toxoplasma gondii. Due to the limited effectiveness and prominent side effects of the existing drugs, there is a dire need for the discovery of new therapeutic options in the treatment of toxoplasmosis. In this study, five essential oils (EO) were screened for their anti-parasitic activity against $T$. gondii. The cytotoxicity of essential oils was evaluated using the MTT assay on human foreskin fibroblast cells. The $\mathrm{CC}_{50}$ values of Eucalyptus globulus EO, Cupressus sempervirens EO, Citrus aurantifolia EO, Melaleuca alternifolia EO, and Pelargonium X. asperum (Pa) EO were found to be $22.74,7.25,15.01,6.26$, and $4.77 \mathrm{mg} / \mathrm{mL}$, respectively. Only $P a E O$ exhibited antiparasitic activity, and inhibited the growth of $T$. gondii in a dose-dependent manner. In addition, treatment with $\mathrm{PaEO}$, was found to reduce the volume of $T$. gondii tachyzoites and make their membrane surfaces rough. These results showed that $P a E O$ was able to inhibit the growth of $T$. gondii by reducing invasion, which may be due to its detrimental effect on the ability of tachyzoites to move. These findings suggest that PaEO could be a potential anti-T. gondii drug, which may facilitate the development of new and effective treatments against toxoplasmosis.

Keywords: Toxoplasma gondii, natural extraction products, drug, development, Pelargonium X. Asperum EO

\section{INTRODUCTION}

Toxoplasma gondii is an opportunistic parasite that infects most warm-blooded animals, causing ophthalmopathy, abortion, stillbirth, and choroidal retinitis (Zhang et al., 2016). The parasite is transmitted to humans through the ingestion of raw meat contaminated with tissue cysts, or through food or water contaminated with oocysts. The oocyst's walls protect the cells from the external environment, making them resistant to the chlorine dioxide and chloramine used to disinfect water (Shapiro et al., 2019). Serious toxoplasmosis outbreaks have occurred in several countries, both in humans and in animals, leading to serious economic and public health problems.

Since the 1950s, a combination of sulfadiazine and pyrimethamine has been the standard therapy for toxoplasmosis (Eyles and Coleman, 1953). Unfortunately, the side effects of this combination 
are serious, and very often, patients cannot complete the entire course of treatment because of drug intolerance. Spiramycin was initially used in the treatment of $T$. gondii infection in 1958. While this drug does reduce motherto-child transmission, its inability to cross the placental barrier means that it is unable to reach an infected fetus (Desmonts and Couvreur, 1974). Clindamycin, clarithromycin, and trimethoprim-sulfamethoxazole (TMX-SMX) have also been used in the treatment of toxoplasmosis. However, overuse of these drugs over the years has led to the emergence of drug resistance (Dunay et al., 2018). Therefore, the development of new drugs to control and treat toxoplasmosis in both humans and animals, is the need of the hour.

Natural products are a good alternative to synthetic molecules for the treatment of T. gondii infections. Products isolated from natural sources are superior to synthetic molecules in terms of their impact on the environment, source of acquisition, and safety profile (Petrovska, 2012). Through long-term interactions and co-evolution with other plants and species in their habitat, certain plants have evolved to produce a large number of structurally diverse secondary metabolites, which possess a variety of ecological functions that are essential for their survival (Mahizan et al., 2019). Essential oils (EOs) are a mixture of secondary metabolites, composed mainly of terpenes, aldehydes, and esters (Swamy et al., 2016). Most hydrophobic molecules that are small can cross biological barriers and biofilms (Costa et al., 2018); prevent infections, inflammation, and spasms; fight bacteria and viruses (Gucwa et al., 2018); and promote cell metabolism and regeneration. Certain components of EOs possess anti-parasitic activity.

An extract prepared from the leaves of Eucalyptus globulus $(E g)$ has been shown to exhibit a significant inhibitory effect on Aggregatibacter actinomycetemcomitans and Porphyromonas gingivalis in vitro (Bankur et al., 2019). In addition, it can also kill Aedes mosquito (Kaura et al., 2019) and inhibit the growth of Giardia lamblia cysts (Dehghani-Samani et al., 2019). Two hydrogenated monoterpenes, extracted from Cupressus sempervirens (Cs) have been shown to possess pesticidal properties against Sitophilus zeamais (Langsi et al., 2020). Citrus aurantifolia ( $\mathrm{Ca}$ ) belonging to the Rutaceae family can effectively ward off mosquitoes (Araujo et al., 2016). Melaleuca alternifolia $\mathrm{EO}(\mathrm{MaEO})$ is a promising candidate for use as a repellent, acaricide, and insecticide (Souza et al., 2016). The Japanese beetle (Popillia japonica) is paralyzed by consuming Pelargonium hortorum, a plant belonging to the same genus as Pelargonium $X$. asperum (Pa) (Ranger et al., 2011). The EOs in these plants exhibit insecticidal, anti-bacterial and anti-fungal properties, among a range of other biological functions.

EOs that were extracted from several plant species have been reported to exhibit activity against $T$. gondii. EO from Thymus broussonetii Boiss, has been shown to reduce prugniaud (Pru) cysts (Dahbi et al., 2010). Bunium persicum (Boiss) EO has been shown to prevent $T$. gondii infection in mice and significantly delay their time of death (Kareshk et al., 2015). These results suggest that EOs may possess anti-T. gondii activity. In order to verify this hypothesis, we screened five EOs from different plants for their anti-T. gondii activity.

\section{MATERIALS AND METHODS}

\section{Cell Culture and Parasite}

T. gondii tachyzoites of the $\mathrm{RH}$ strain, expressing green fluorescence protein (GFP-RH) were maintained in human foreskin fibroblast (HFF) cells, cultured in Dulbecco's modified Eagle's medium (DMEM), supplemented with $100 \mathrm{IU} / \mathrm{mL}$ penicillin and $100 \mu \mathrm{g} / \mathrm{mL}$ streptomycin, along with $10 \%$ heatinactivated fetal bovine serum (FBS). The culture was incubated at $37^{\circ} \mathrm{C}$, in an atmosphere containing $5 \% \mathrm{CO}_{2}$. To isolate the tachyzoites, heavily infected cells were scraped and the parasites were released by passing the cells through a 27 -gauge needle, 3-5 times. Cell debris was removed by passing the mixture through a 3- $\mu \mathrm{m}$ pore membrane filter (Whatman, Thermo Fisher Scientific, Waltham, MA, United States). Tachyzoites were quantified using a hemocytometer before proceeding to further experiments.

\section{Essential Oils}

The EOs were purchased from the French EO manufacturer, Florihana. These included the EOs of $\mathrm{Pa}$ (Lot Number: AM020920MG), Ma (Lot Number: AM020920MG), and Eg (Lot Number: E060420ES), extracted from their leaves; the EO of Ca (Lot Number: B180719BR), extracted from the plant zest; and the EO of Cs (Lot Number: A010420F), extracted from its branches. All EOs were extracted by steam distillation. The main ingredients and chemical components of each EO are summarized in Supplementary Table 1. All EOs were dissolved in dimethyl sulfoxide (DMSO) in a 1:1 ratio. The solutions were then diluted with DMEM, such that the final concentration of DMSO in the samples used in the experiment was lower than $1.56 \% \mathrm{v} / \mathrm{v}$.

\section{Cytotoxicity Assay}

The cytotoxicity of all these EOs was evaluated in an HFF cell line, using a CellTiter 96 ${ }^{\circledR}$ AQueous One Solution Cell Proliferation Assay (Promega Corp., Madison, WI, United States), according to the manufacturer's instructions. HFF cells $\left(1 \times 10^{5}\right.$ cells/well $)$ were cultured in 96 -well plates at $37^{\circ} \mathrm{C}$, in an atmosphere containing $5 \% \mathrm{CO}_{2}$, for $24 \mathrm{~h}$. The cells were treated with varying concentrations of EOs or sulfamethoxazole (SMZ), and incubated for $24 \mathrm{~h}$. Different concentrations of each EO were added to the wells. A $1.56 \%$ solution of DMSO in DMEM was used as the vehicle control. After incubating for $48 \mathrm{~h}, 20 \mu \mathrm{L}$ of MTS solution, containing phenazine ethyl sulfate, was added to each well, and incubated for $3 \mathrm{~h}$ at $37^{\circ} \mathrm{C}$. Absorbance was measured at $490 \mathrm{~nm}$ using an iMark $^{\mathrm{TM}}$ Microplate Absorbance Reader (BioRad, Hercules, CA, United States). Wells containing cells treated only with DMEM were used as the negative control (Montazeri et al., 2019). The $50 \%$ cytotoxic concentrations $\left(\mathrm{CC}_{50}\right)$ were calculated using Graph Pad Prism 8.0. The cytotoxicity experiment was performed in triplicate, using three separate plates.

\section{Anti-T. gondii Activity of EOs Evaluated by a Plaque Assay}

One-hundred freshly released tachyzoites were added to HFF monolayers in 6-well plates, in DMEM with 2\% FBS. They were 
incubated at $37^{\circ} \mathrm{C}$, in an atmosphere containing $5 \% \mathrm{CO}_{2}$, for $4 \mathrm{~h}$. Then, the medium containing extracellular parasites was removed, and fresh medium containing various concentrations of EOs, or $1.56 \%$ DMSO in DMEM (vehicle control) was added to each well. Uninfected and untreated wells were used as blank controls. After 7 days, HFF cells were washed three times with PBS, fixed with methanol for $10 \mathrm{~min}$, and stained with $0.1 \%$ crystal violet for $30 \mathrm{~min}$. After washing three times with phosphate buffered saline (PBS) and drying naturally (Bai et al., 2018), the plaques formed by tachyzoites were examined by microscopy.

\section{Anti-T. gondii Activity of PaEO Evaluated by an Intracellular Growth Assay}

A total of $10^{4}$ freshly released tachyzoites of the GFP-RH strain were added to HFF monolayers in 6-well plates, in DMEM with $2 \% \mathrm{FBS}$. Cells were incubated at $37^{\circ} \mathrm{C}$ in an atmosphere containing $5 \% \mathrm{CO}_{2}$, for $4 \mathrm{~h}$. The medium containing extracellular parasites was removed and fresh medium containing either $\mathrm{PaEO}$ $(3.55,1.77,0.89,0.44,0.22 \mathrm{mg} / \mathrm{mL})$, vehicle control, or SMZ (positive control) was added to each well. After $32 \mathrm{~h}$, the growth of GFP-RH was observed and photographed under a fluorescence microscope. Growth of GFP-RH was calculated using Image-ProExpress.

\section{Effect of PaEO on Cell Invasion by T. gondii}

Two-color invasion experiments were performed as described by Augusto et al. (2018). A 6-well plate of HFF cells was prepared, and $3 \mathrm{~mL}$ of $2 \%$ FBS in DMEM was added to each well. Then, $10^{4} \mathrm{RH}$ and $3.55 \mathrm{mg} / \mathrm{mL} \mathrm{PaEO}$ were added simultaneously to the wells, allowing the tachyzoites to invade host cells for 20, 40 , or $60 \mathrm{~min}$. The supernatant was gently removed, fixed with $2 \mathrm{~mL}$ methanol for $10 \mathrm{~min}$, washed three times with PBS, added to $300 \mu \mathrm{L}$ of a $5 \%$ solution of bovine serum albumin in PBS (BSA/PBS), blocked for $1 \mathrm{~h}$, and washed three times with PBS. Mouse anti-Toxoplasma SAG1 monoclonal antibodies (mAb), diluted $(1: 1,000)$ with a $1 \%$ BSA/PBS solution, were added to each well, and incubated at room temperature for $2 \mathrm{~h}$. Then, goat antimouse IgG H\&L(FITC) secondary antibodies, diluted $(1: 1,000)$ in $1 \% \mathrm{BSA} / \mathrm{PBS}$, were added to 6 -well plates and incubated at room temperature for $2 \mathrm{~h}$. After washing thrice with PBS, 300 $\mu \mathrm{L}$ of $0.2 \%$ Triton $\mathrm{X}-100$ was added, and the mixture was left for $30 \mathrm{~min}$. Cells were then gently washed three times with PBS, and $300 \mu \mathrm{L}$ of a $5 \%$ BSA/PBS solution was added dropwise for a second blocking. The antibodies were added as per the procedure described earlier, this time using goat anti-mouse IgG H\&L (Alexa Fluor ${ }^{\circledR} 568$ ) (ab175473) instead of the goat anti-mouse IgG H\&L(FITC). Finally, $300 \mu \mathrm{L}$ of $30 \%$ glycerol was added to each well. Five visual fields were randomly selected for observation under the $40 \times$ objective of the fluorescence microscope and the parasites in each field were counted. Three repetitions were performed to increase the accuracy of the experiment.

Tachyzoites that were unable to successfully invade the cells were dyed green by goat anti-mouse IgG H\&L (FITC), while all tachyzoites in the field of vision (including the non-invading and successfully invading ones) were stained red by goat antimouse IgG H\&L (Alexa Fluor ${ }^{\circledR}$ 568) (ab175473). The difference between the tachyzoites of the two colors is termed as the absolute invasion number of tachyzoites. The ratio of the invasion number to the total number of tachyzoites is termed as the invasion rate of tachyzoites.

\section{Assessment of Tachyzoite Ultrastructure Using Scanning Electron Microscopy}

To determine differences in the ultrastructure of tachyzoites after treatment, 1,000 purified tachyzoites were treated with $\mathrm{PaEO}$, and incubated at $37^{\circ} \mathrm{C}$ for $8 \mathrm{~h}$. They were then washed twice with PBS, and fixed overnight, using $2.5 \%$ glutaraldehyde at room temperature. Gradient dehydration was carried out, using different concentrations of ethanol. The tachyzoites were coated with gold (20-30 $\mathrm{nm})$ and observed by scanning electron microscopy.

\section{Statistical Analysis}

All data were analyzed using GraphPad Prism 8.0. The antiparasitic activity of the EOs was analyzed using an unpaired $t$-test, while the cell invasion data were processed using multiple $t$-tests, to compare the results of the test groups and those of the control group $\left({ }^{*} P<0.05,{ }^{* *} P<0.01,{ }^{* * *} P<0.001\right)$.

\section{RESULTS}

\section{Cytotoxicity of EOs}

It was necessary to evaluate the cytotoxic potential of each EO on the same cell line as that intended to be used in the subsequent assays. The concentration that induced $50 \%$ HFF cell mortality $\left(\mathrm{CC}_{50}\right)$ was determined using an MTT assay, and analyzed using GraphPad Prism 8.0. The $\mathrm{CC}_{50}$ values of $\mathrm{EgEO}, \mathrm{CsEO}, \mathrm{CaEO}$, $\mathrm{MaEO}$, and $\mathrm{PaEO}$ were found to be $22.74,7.25,15.01,6.26$, and $4.77 \mathrm{mg} / \mathrm{mL}$, respectively (Table $\mathbf{1}$ and Figure $\mathbf{1}$ ).

\section{In vitro Anti-parasitic Activity of EOs}

A plaque test was used to screen the anti-T. gondii activity of the five EOs. As seen in Figure 2, we found that the plaques visible were fewer in number and smaller in size after treatment with two different concentrations of $\mathrm{PaEO}$, as compared to those in the DMSO-treated and untreated groups. However, no significant reduction in plaque number or size was found in the samples

TABLE 1 | Cytotoxic effects of five EOs.

EOs

$\mathrm{CC}_{50}(\mathrm{mg} / \mathrm{mL})(95 \%$ confidence intervals)

Citrus aurantifolia

$15.01(10.28-22.40)$

Cupressus sempervirens

Eucalyptus Globulus

Melaleuca alternifolia

7.25 (5.26-10.01)

22.74 (14.82-36.46)

$6.26(4.721-8.282)$

Pelargonium X. Asperum

$4.77(2.075-10.47)$

Results are presented as the mean $\mathrm{CC}_{50}$ (cytotoxicity concentration 50\%) values obtained from three independent experiments. 


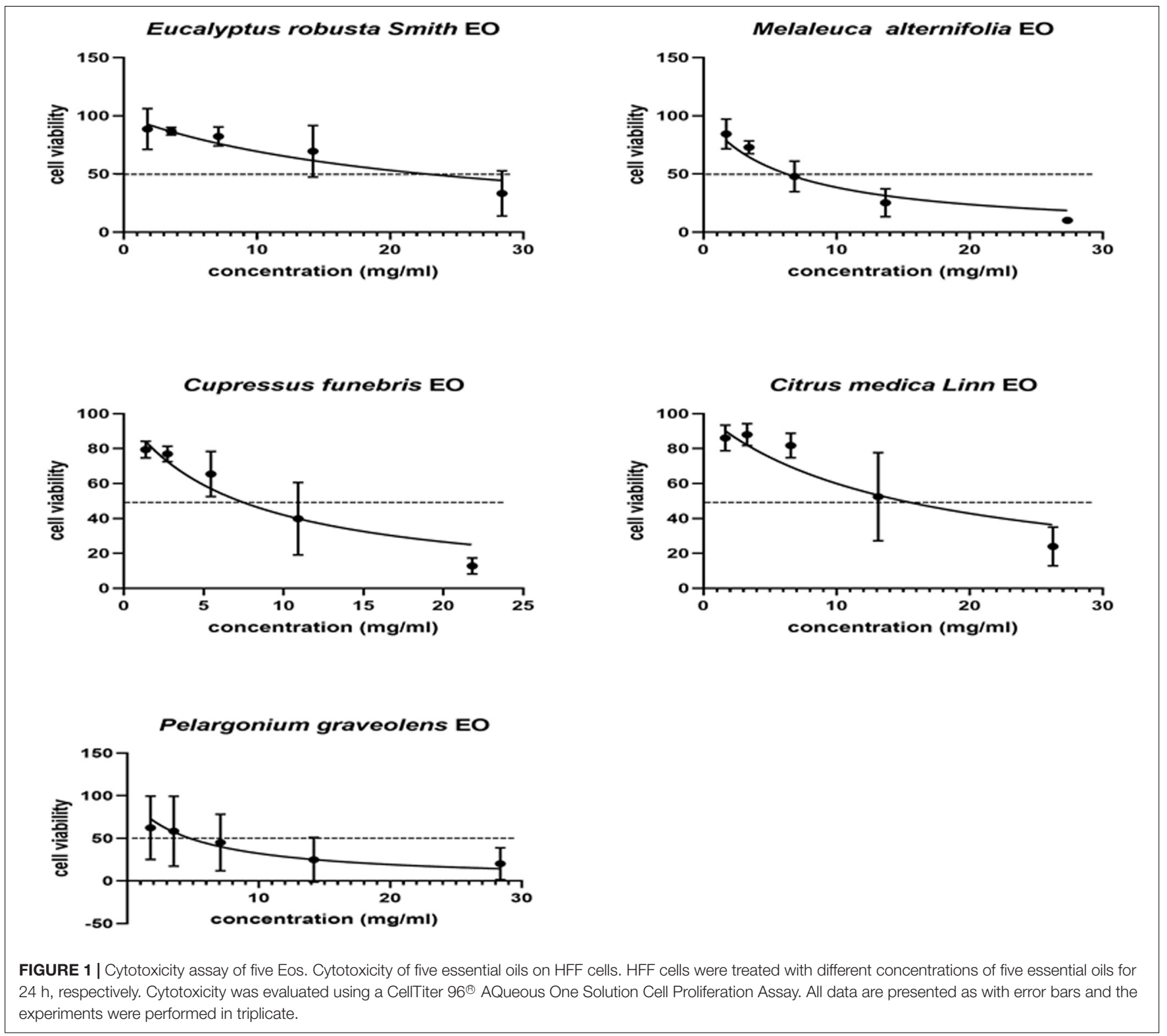

treated with $\mathrm{ErEO}, \mathrm{CfEO}, \mathrm{CmEO}$, and $\mathrm{MaEO}$ (data not shown). These results indicate that $\mathrm{PaEO}$ is able to inhibit the growth of $\mathrm{RH}$ within safe concentrations, while the other four EOs exhibit no direct anti-parasitic activity. To evaluate the effect of $\mathrm{PaEO}$ concentration on anti-parasitic activity, five different concentrations were compared using an in vitro inhibition assay. We found that the growth of T. gondii was inhibited by each of the concentrations of $\mathrm{PaEO}$ tested (Figure 3A), and the activity increased in a dose-dependent manner (Figure 3B). The results show that the growth of $T$. gondii was significantly reduced after treatment with 3.55 and $1.77 \mathrm{mg} / \mathrm{mL}$ of $\mathrm{PaEO}(68.17$ vs. $1,278 ; 342.3$ vs. $1,278, P<0.0001)$, as compared to the untreated and $1.56 \%$ DMSO-treated groups. For the groups treated with 0.89 and $0.44 \mathrm{mg} / \mathrm{mL} \mathrm{PaEO}$, the differences were also significant ( 830.3 vs. $1,278,942.8$ vs. $1,278, P<0.01$ ). The inhibition of T. gondii was much more significant in the groups treated with
3.55 and $1.77 \mathrm{mg} / \mathrm{mL} P a E O$, than in those treated with SMZ (68.17 vs. $490.1,342.3$ vs. $490.1, P<0.01$ ). The $\mathrm{IC}_{50}$ of $P a \mathrm{EO}$ was found to be $1.426 \mathrm{mg} / \mathrm{mL}$.

\section{Effect of PaEO on Cell Invasion by T. gondii}

As summarized in Figure 4, in the $3.55 \mathrm{mg} / \mathrm{mL} \mathrm{PaEO}$ treatment group, the $T$. gondii invasion rates at 20,40 , and 60 min postinfection were found to be $25.98,32.01$, and $41.18 \%$, respectively. In the untreated groups, invasion rates were found to be $38.50,51.51$, and $67.64 \%$, respectively, at the three time points. Compared to the untreated group, $\mathrm{PaEO}$ significantly reduced the invasion of T. gondii, especially after treatment for $60 \mathrm{~min}$ $(P<0.001)$. The inhibitory effect was observed to increase as the treatment time increased. No change in the invasion rate of 


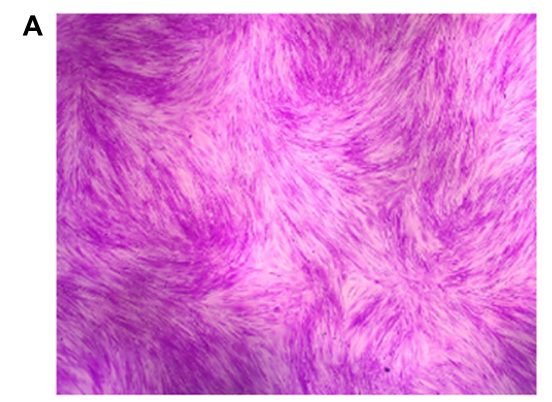

B

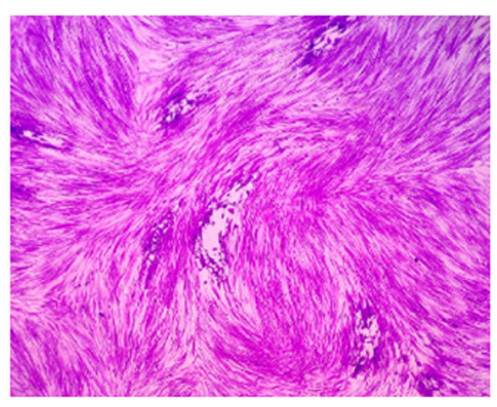

C

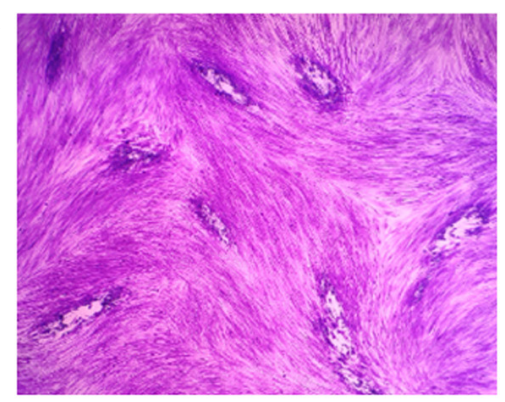

D

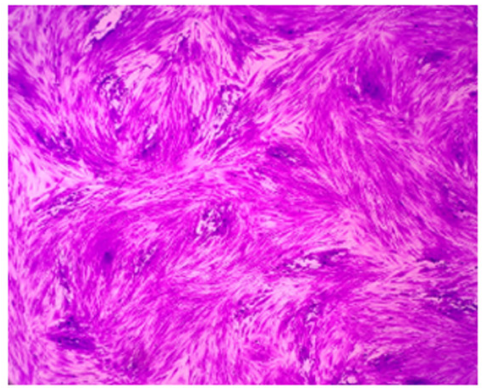

E

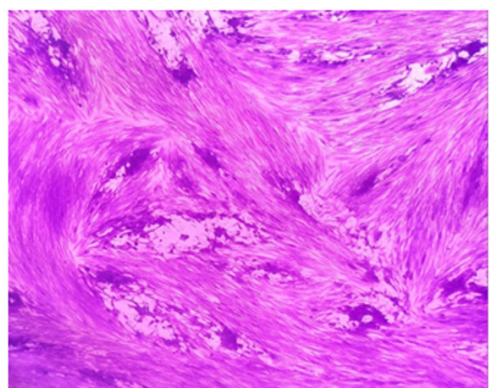

FIGURE 2 | Anti-T. gondii activity of EOs evaluated by plaque assay. Images of T. gondii plaque under different concentration of Pelargonium graveolens EO. (A) HFF cells were not infected and treated. (B) HFF cells were infected by T. gondii and treated with $1.77 \mathrm{mg} / \mathrm{mL}$ PaEO. (C) HFF cells were infected by T. gondii and treated with $0.44 \mathrm{mg} / \mathrm{mL}$ PaEO. (D) HFF cells were infected by T. gondii and untreated. (E) HFF cells were infected by T. gondii and treated with DMSO.

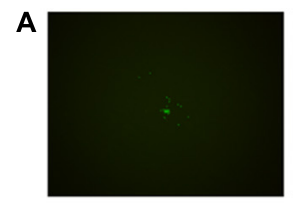

$\mathbf{a}$

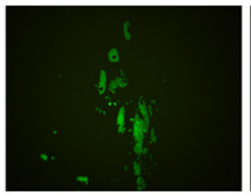

e

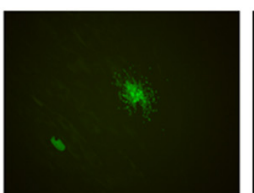

b

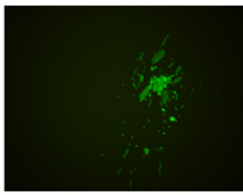

f

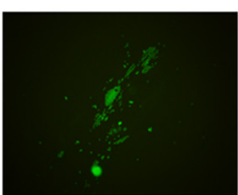

c

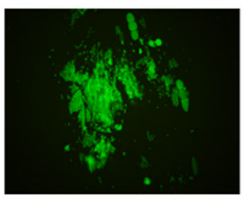

g

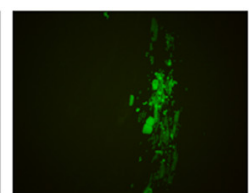

d

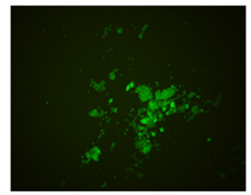

h

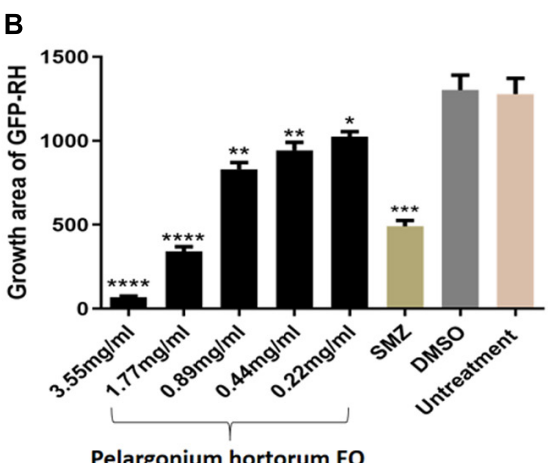

Pelargonium hortorum EO

FIGURE 3 | Anti-T. gondii activity of PaEO evaluated by intracellular growth assay. (A) Images of growth area of $T$. gondii treated with different concentrations of $P a E O$ in vitro. Fluorescence area shows the growth of $T$. gondii treated with different concentrations of $P a E O$. (a-e) Different concentrations of $P a E O$, (a) 3.55 mg/mL; (b) $1.77 \mathrm{mg} / \mathrm{mL}$; (c) $0.89 \mathrm{mg} / \mathrm{mL}$; (d) $0.44 \mathrm{mg} / \mathrm{mL}$; (e) $0.22 \mathrm{mg} / \mathrm{mL}$; (f) SMZ; (g) DMSO; (h) no treatment. (B) The inhibition of PaEO on T. gondii infections. The inhibition of infection for $\mathrm{RH}$-GFP was measured by fluorescence area. Each bar represents the mean $\pm S D$ of three wells per group. ${ }^{\star} P<0.05$, ${ }^{\star \star} P<0.01$, ${ }^{\star \star \star} P<0.001,{ }^{\star \star \star \star} P<0.0001$ compared with untreated group.

T. gondii was observed in any group treated with DMSO, across all experiments.

\section{Tachyzoite Ultrastructure Analysis}

The SEM results showed that the surface of the tachyzoites became rough after treatment with $\mathrm{PaEO}$. This was markedly different from the observations made in the untreated group (Figure 5). The tachyzoites also appeared smaller and shrunken after treatment with $\mathrm{PaEO}$, as compared to those in the untreated and DMSO-treated groups.

\section{DISCUSSION}

Due to the limitations of the drugs currently available for the treatment of toxoplasmosis, and the lack of drugs for chronic infections, the search for safer and more effective anti-T. gondii drugs is extremely important. Studying natural plant extracts is a good starting point for the development of new anti-parasitic drugs. In this study, the anti-T. gondii activity of five EOs was screened and evaluated in vitro. Among these EOs, PaEO $\left(\mathrm{IC}_{50}=1.426 \mathrm{mg} / \mathrm{mL}\right)$ was found to be the most potent inhibitor 


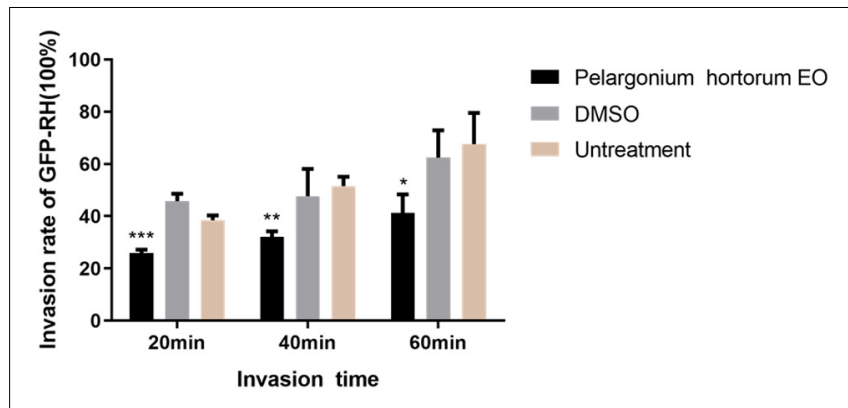

FIGURE 4 | Effect of $P a E O$ on the invasion of $T$. gondii. The percentage of tachyzoites invading cells after treated with PaEO for 20, 40, 60 min, respectively. Significant differences between the treated groups and untreated group are indicated. ${ }^{\star} P<0.05,{ }^{\star \star} P<0.01$, ${ }^{\star \star \star} P<0.001$ compared with untreated group.

of T. gondii tachyzoite growth. The other four EOs did not exhibit any activity against $T$. gondii.

To determine the mechanism by which $\mathrm{PaEO}$ inhibits the growth of $T$. gondii, invasion experiments were carried out. On treatment with $\mathrm{PaEO}$, the invasion rate of tachyzoites was found to decrease over time. It was therefore inferred that $\mathrm{PaEO}$ may be able to inhibit the proliferation of tachyzoites by restricting their ability to invade host cells. $\mathrm{PaEO}$ was able to reduce the number of plaques in the plaque assay, by inhibiting the invasion of host cells by $T$. gondii. Many plants of the genus Pelargonium show therapeutic effects against respiratory infections, fever, dysentery, and wounds (Ranger et al., 2011). Previous studies have shown that they have the ability to control the growth of Spodoptera littoralis (Farag et al., 2012), and the lone star tick, Amblyomma americanum (Tabanca et al., 2013). As summarized in Supplementary Material 1, linalool and geraniol are unique chemical constituents found in $\mathrm{PaEO}$. Zhang et al. predicted, through chemical-gene interaction analysis, that geraniol has 38 target genes, which are closely linked to a series of physiological activities (Zhang et al., 2019). DsbA, a virulence regulator, required by Shigella sonnei for survival, can be competitively inhibited by geraniol (Mirza et al., 2018). It has been reported that when the calcium-dependent protein kinase 1 (CDPK1) gene of $T$. gondii is suppressed, the gliding and motility of tachyzoites are affected (Johnson et al., 2012). Interestingly, linalool has also been shown to be an effective anesthetic in Hydra (Goel et al., 2019). Therefore, we speculate that $P a E O$ may be able to target the exercise-related genes of T. gondii. In addition, the anesthetic activity is consistent with that of synthetic L-quisqualic acid, which is considered to be an agonist of excitatory amino acid receptors. It was speculated that Japanese beetles may be paralyzed due to excessive muscle excitement, caused by the L-quisqualic acid in zonal geranium (Ranger et al., 2011). Zonal geranium and $\mathrm{Pa}$ belong to the same geranium family. As a protozoan, T. gondii does not have neuromuscular junctions like insects do. However, $\mathrm{PaEO}$ may act instead by inhibiting a target essential for the movement of T. gondii tachyzoites and thereby, inhibit the invasion of cells by T. gondii.

The results of the SEM experiment show that after treatment with $\mathrm{PaEO}$, the tachyzoites became significantly smaller and contracted, and their cell membrane became rough. EOs are a mixture of many components, and can destroy the integrity of biofilms (Gucwa et al., 2018). Essid et al. (2017) speculated that $\mathrm{PaEO}$ may be able to interfere with membrane permeability in Candida strains, by inhibiting the formation of long chain fatty acids (especially oleic acid), which aid cell membrane penetration, and effectively allow the parasite to carry out its biological activity (Ben Hsouna and Hamdi, 2012; Essid et al., 2017). After treatment with geranium tuber extract, the capsules of Cryptococcus neoformans were found to have become thinner, and the surface of $C$. neoformans was found to have shrunk, when evaluated by electron microscopy. This shrinking may be a result of dehydration, caused by the high phenol content (Samie et al., 2019). Phenol is also an important component of $\mathrm{PaEO}$, and may affect the membrane surface of $T$. gondii, thereby inhibiting the parasite's movement and ability to invade cells. The electron microscopy results clearly showed that $\mathrm{PaEO}$ damaged the cell membrane of the tachyzoites and caused them to undergo atrophy. We predict that this damage may be related to the movement of tachyzoites, which in turn affected the invasion of HFF cells, and thereby reduced the number of plaques. However, the specific mechanism is still unclear, and more in-depth research is required to gain a better understanding.
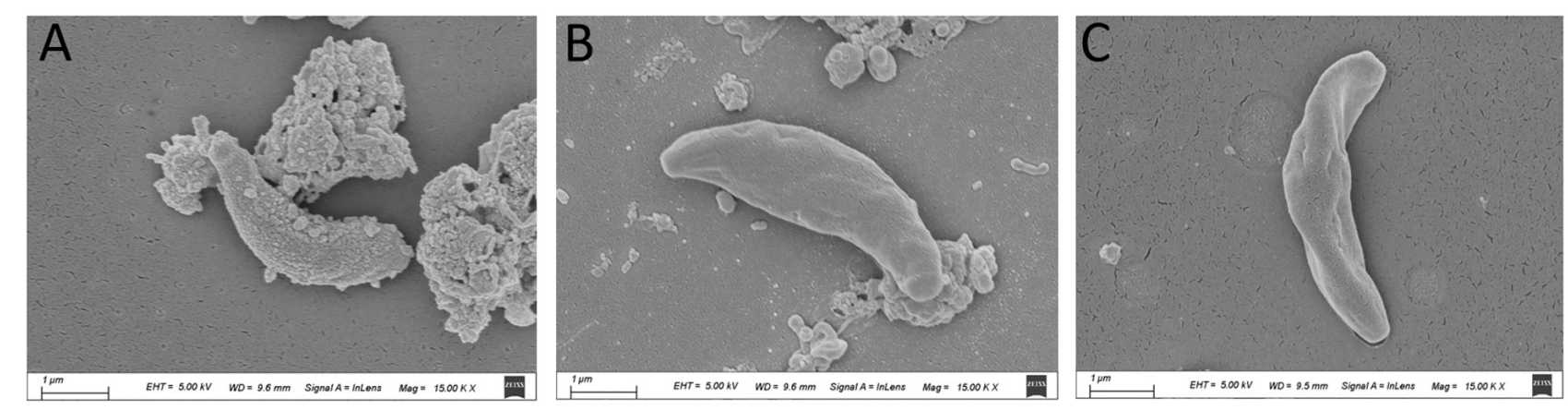

FIGURE 5 | Scanning electron microscopy assay. The cells were treated with $1.77 \mathrm{mg} / \mathrm{mL}$ PaEO (A), DMSO (C), or untreated (B). After treated by PaEO, the tachyzoites in the treated group shrunk and the membrane surface became rough comparing to those untreated tachtzoites, Scale bars: $1 \mu \mathrm{m}$. 


\section{CONCLUSION}

In conclusion, natural extracts are a promising source for the discovery of new drugs. Our research showed that $\mathrm{PaEO}$ can inhibit T. gondii at a safe concentration. This inhibitory effect may be due to the destruction of cell membranes of $T$. gondii by $\mathrm{PaEO}$ and the resulting effect on its mobility. However, the target protein and mechanism of action of $\mathrm{PaEO}$ on $T$. gondii are still unclear and warrant further studies.

\section{DATA AVAILABILITY STATEMENT}

The original contributions presented in the study are included in the article/Supplementary Material, further inquiries can be directed to the corresponding author/s.

\section{AUTHOR CONTRIBUTIONS}

S-YH and NY conceived and designed the study. NY, J-KH, MP, $\mathrm{Z}-\mathrm{FH}$, and Y-MF performed the laboratory analyses. $\mathrm{AD}$ and

\section{REFERENCES}

Araujo, A. F., Ribeiro-Paes, J. T., Deus, J. T., Cavalcanti, S. C., Nunes Rde, S., Alves, P. B., et al. (2016). Larvicidal activity of Syzygium aromaticum (L.) Merr and Citrus sinensis (L.) Osbeck essential oils and their antagonistic effects with temephos in resistant populations of Aedes aegypti. Mem. Inst. Oswaldo Cruz 111, 443-449. doi: 10.1590/0074-02760160075

Augusto, L., Martynowicz, J., Staschke, K. A., Wek, R. C., and Sullivan, W. J. Jr. (2018). Effects of PERK eIF $2 \alpha$ Kinase Inhibitor against Toxoplasma gondii. Antimicrob. Agents Chemother. 62, e1442-18. doi: 10.1128/AAC. 01442-18

Bai, M. J., Wang, J. L., Elsheikha, H. M., Liang, Q. L., Chen, K., Nie, L. B., et al. (2018). Functional characterization of dense granule proteins in Toxoplasma gondii RH strain using CRISPR-Cas9 system. Front. Cell. Infect. Microbiol. 8:300. doi: $10.3389 /$ fcimb.2018.00300

Bankur, P. K., Mathew, M., Almalki, S. A., Jalaluddin, M., Jayanti, I., and Durgaraju, M. (2019). An in vitro evaluation of antibacterial efficacy of various concentration of eucalyptus globulus leaf extract on periodontal pathogens. J. Contemp. Dent. Pract. 20, 1041-1044. doi: 10.5005/jp-journals-100242639

Ben Hsouna, A., and Hamdi, N. (2012). Phytochemical composition and antimicrobial activities of the essential oils and organic extracts from Pelargonium graveolens growing in Tunisia. Lipids Health Dis 11:167. doi: 10.1186/1476-511X-11-167

Costa, S., Cavadas, C., Cavaleiro, C., Salgueiro, L., and Sousa, M. D. C. (2018). In vitro susceptibility of Trypanosoma brucei brucei to selected essential oils and their major components. Exp. Parasitol. 190, 34-40. doi: 10.1016/j.exppara. 2018.05.002

Dahbi, A., Bellete, B., Flori, P., Hssaine, A., Elhachimi, Y., Raberin, H., et al. (2010). The effect of essential oils from Thymus broussonetii Boiss on transmission of Toxoplasma gondii cysts in mice. Parasitol. Res. 107, 55-58. doi: 10.1007/ s00436-010-1832-z

Dehghani-Samani, A., Madreseh-Ghahfarokhi, S., Dehghani-Samani, A., and Pirali, Y. (2019). In-vitro antigiardial activity and GC-MS analysis of Eucalyptus globulus and Zingiber officinalis essential oils against Giardia lamblia cysts in simulated condition to human's body. Ann. Parasitol. 65, 129-138.

Desmonts, G., and Couvreur, J. (1974). Toxoplasmosis in pregnancy and its transmission to the fetus. J. Bull. N. Y. Acad. Med. 50, 146-159. doi: 10.1097/ 00006254-197409000-00007
J-PT analyzed the data. S-YH drafted the first version of the manuscript. All authors critically appraised and interpreted the results and provided feedback on the manuscript, and read and approved the final version.

\section{FUNDING}

The sample collection and some experiment were supported by the Outstanding Youth Foundation of Jiangsu Province of China (BK20190046), The China Postdoctoral Science Foundation (2020M671615), the Science and Technology Major Project of Zhejiang Province, China (No. 2012C12009-2), and the Priority Academic Program Development of Jiangsu Higher Education Institutions (Veterinary Medicine).

\section{SUPPLEMENTARY MATERIAL}

The Supplementary Material for this article can be found online at: https://www.frontiersin.org/articles/10.3389/fcell.2021. 616340/full\#supplementary-material

Dunay, I. R., Gajurel, K., Dhakal, R., Liesenfeld, O., and Montoya, J. G. (2018) Treatment of Toxoplasmosis: historical perspective, animal models, and current clinical practice. Clin. Microbiol. Rev. 31, e00057-17. doi: 10.1128/CMR. 00057-17

Essid, R., Hammami, M., Gharbi, D., Karkouch, I., Hamouda, T. B., Elkahoui, S., et al. (2017). Antifungal mechanism of the combination of Cinnamomum verum and Pelargonium graveolens essential oils with fluconazole against pathogenic Candida strains. Appl. Microbiol. Biotechnol. 101, 6993-7006. doi: 10.1007/ s00253-017-8442-y

Eyles, D. E., and Coleman, N. (1953). Synergistic effect of sulfadiazine and daraprim against experimental toxoplasmosis in the mouse. Antibiot. Chemother. (Northfield) 3, 483-490.

Farag, M., Ahmed, M. H., Yousef, H., El-Badawey, S. S., Abd El-Ghany, M. A., and Abdel-Rahman, A. A. (2012). Repellent and insecticide activity of Pelargonium $x$ hortorum against Spodoptera littoralis (Boisd.). Z. Naturforsch. C J. Biosci. 67, 398-404. doi: 10.1515/znc-2012-7-807

Goel, T., Wang, R., Martin, S., Lanphear, E., and Collins, E.-M. S. (2019). Linalool acts as a fast and reversible anesthetic in Hydra. PLoS One 14:e0224221. doi: 10.1371/journal.pone.0224221

Gucwa, K., Milewski, S., Dymerski, T., and Szweda, P. (2018). Investigation of the Antifungal Activity and Mode of Action of Thymus vulgaris, Citrus limonum, Pelargonium graveolens, Cinnamomum cassia, Ocimum basilicum, and Eugenia caryophyllus Essential Oils. Molecules 23, 1116. doi: 10.3390/ molecules23051116

Johnson, S. M., Murphy, R. C., Geiger, J. A., Derocher, A. E., Zhang, Z., Ojo, K. K., et al. (2012). Development of Toxoplasma gondii calcium-dependent protein kinase 1 (TgCDPK1) inhibitors with potent anti-toxoplasma activity. J. Med. Chem. 55, 2416-2426. doi: 10.1021/jm201713h

Kareshk, A., Keyhani, A., Mahmoudvand, H., Tavakoli Oliaei, R., Asadi, A., Andishmand, M., et al. (2015). Efficacy of the Bunium persicum (Boiss) essential oil against acute Toxoplasmosis in mice model. Iran. J. Parasitol. 10, 625-631.

Kaura, T., Mewara, A., Zaman, K., Sharma, A., Agrawal, S. K., Thakur, V., et al. (2019). Utilizing larvicidal and pupicidal efficacy of eucalyptus and neem oil against Aedes mosquito: an approach for mosquito control. Trop. Parasitol. 9, $12-17$.

Langsi, J. D., Nukenine, E. N., Oumarou, K. M., Moktar, H., Fokunang, C. N., and Mbata, G. N. (2020). Evaluation of the insecticidal activities of $\alpha$-Pinene and 3Carene on Sitophilus zeamais Motschulsky (Coleoptera: Curculionidae). Insects 11:540. doi: 10.3390/insects 11080540 
Mahizan, N. A., Yang, S. K., Moo, C. L., Song, A. A., Chong, C. M., Chong, C. W., et al. (2019). Terpene derivatives as a potential agent against Antimicrobial Resistance (AMR) pathogens. Molecules 24:2631. doi: 10.3390/ molecules24142631

Mirza, Z., Hasan, T., Seidel, V., and Yu, J. (2018). Geraniol as a novel antivirulence agent against bacillary dysentery-causing Shigella sonnei. Virulence 9, 450-455. doi: 10.1080/21505594.2017.1412031

Montazeri, M., Emami, S., Asgarian-Omran, H., Azizi, S., Sharif, M., Sarvi, S., et al. (2019). In vitro and in vivo evaluation of kojic acid against Toxoplasma gondii in experimental models of acute toxoplasmosis. Exp. Parasitol. 200, 7-12. doi: 10.1016/j.exppara.2019.03.009

Petrovska, B. B. (2012). Historical review of medicinal plants' usage. Pharmacogn. Rev. 6, 1-5. doi: 10.4103/0973-7847.95849

Ranger, C. M., Winter, R. E., Singh, A. P., Reding, M. E., Frantz, J. M., Locke, J. C., et al. (2011). Rare excitatory amino acid from flowers of zonal geranium responsible for paralyzing the Japanese beetle. Proc. Natl. Acad. Sci. U.S.A. 108, 1217-1221. doi: 10.1073/pnas.1013497108

Samie, S., Trollope, K. M., Joubert, L. M., Makunga, N. P., and Volschenk, H. (2019). The antifungal and Cryptococcus neoformans virulence attenuating activity of Pelargonium sidoides extracts. J. Ethnopharmacol. 235, 122-132. doi: 10.1016/j.jep.2019.02.008

Shapiro, K., Bahia-Oliveira, L., Dixon, B., Dumètre, A., De Wit, L. A., Vanwormer, E., et al. (2019). Environmental transmission of Toxoplasma gondii: Oocysts in water, soil and food. Food Waterborne Parasitol. 15:e00049. doi: 10.1016/j. fawpar.2019.e00049

Souza, C. F., Baldissera, M. D., Vaucher, R. A., Lopes, L. Q., Vizzotto, B. S., and Raffin, R. P., et al. (2016). In vivo bactericidal effect of Melaleuca alternifolia essential oil against Aeromonas hydrophila: Silver catfish (Rhamdia quelen) as an experimental model. Microb. Pathog. 98, 82-87. doi: 10.1016/j.micpath.2016. 07.002

Swamy, M. K., Akhtar, M. S., and Sinniah, U. R. (2016). Antimicrobial properties of plant essential oils against human pathogens and their mode of action: an updated review. Evid. Based Complement. Alternat. Med. 2016:3012462. doi: $10.1155 / 2016 / 3012462$

Tabanca, N., Wang, M., Avonto, C., Chittiboyina, A. G., Parcher, J. F., Carroll, J. F., et al. (2013). Bioactivity-guided investigation of geranium essential oils as natural tick repellents. J. Agric. Food Chem. 61, 4101-4107. doi: 10.1021/ jf400246a

Zhang, X., Jin, L., Cui, Z., Zhang, C., Wu, X., Park, H., et al. (2016). Antiparasitic effects of oxymatrine and matrine against Toxoplasma gondii in vitro and in vivo. Exp. Parasitol. 165, 95-102. doi: 10.1016/j.exppara.2016.03.020

Zhang, Y.-F., Huang, Y., Ni, Y.-H., and Xu, Z.-M. (2019). Systematic elucidation of the mechanism of geraniol via network pharmacology. Drug Des. Devel. Ther. 13, 1069-1075. doi: 10.2147/dddt.s189088

Conflict of Interest: The authors declare that the research was conducted in the absence of any commercial or financial relationships that could be construed as a potential conflict of interest.

Copyright (c) 2021 Huang, Yao, He, Pan, Hou, Fan, Du and Tao. This is an openaccess article distributed under the terms of the Creative Commons Attribution License (CC BY). The use, distribution or reproduction in other forums is permitted, provided the original author(s) and the copyright owner(s) are credited and that the original publication in this journal is cited, in accordance with accepted academic practice. No use, distribution or reproduction is permitted which does not comply with these terms. 